\title{
Entre el universalismo y el relativismo Reposicionamiento de las ciencias sociales latinoamericanas
}

\author{
Between universalism and relativism
}

Repositioning Latin American social sciences

Marcelo Arnold-Cathalifaud ${ }^{*}$

\begin{abstract}
Resumen: Esta presentación expone las condiciones actuales de la producción de ciencias sociales latinoamericanas y las expectativas que se tienen respecto de ellas, analiza algunos obstáculos que se interponen a nuestras producciones regionales, discute las argumentaciones que colocan en entredicho el carácter universalista de las ciencias sociales y se comentan algunos ejemplos de desarrollos locales de ciencias sociales que han alcanzado un impacto global. Finalmente, se proponen algunas estrategias que podrían contribuir para remontar a nivel global nuestras producciones de ciencias sociales.
\end{abstract}

Palavras-clave: Latinoamérica; conocimientos; ciencias sociales; sociedad; globalización

Abstract: This paper presents the current conditions of production in social sciences in Latin America, and the expectations regarding this branch of knowledge. It examines some of the barriers that hinder its regional development, and it discusses the arguments that call into question the global nature of social sciences, introducing some examples of local development with global impact. At last, it suggests some strategies that might help our production in social sciences reach a global scale.

Keywords: Latin America; knowledge; social science; society; globalization

* Doctor en Sociología, antropólogo social y magíster en Ciencias Sociales, profesor titular de la Universidad de Chile. Sus áreas de investigación son: teoría de los sistemas sociales (sociopoiesis), epistemología constructivista, estudios organizacionales, complejidades emergentes y sociedad contemporánea. Entre sus trabajos recientes se encuentran: En las vísperas de una revolución ignorada (Chile, 2011); Las amenazas ambientales (Chile, 2010); Imágenes de la complejidad contemporánea (Perú, 2009); La nueva teoría social en Hispanoamérica (México, 2008); Las organizaciones desde la teoría de los sistemas sociopoiéticos (Chile, 2008); Sexualidad en la tercera edad (Brasil, 2008); Algunos efectos de procesos acelerados de modernización (España, 2008); Young people's images of old age in Chile (USA, 2008); Desafios para una antropología del siglo veintiuno (2007); Colaboración, cultura y desarrollo (2007); Sociedad y teoría de sistemas (2007); O construtivismo sistêmico nas ciências humanas e sociais (Brasil, 2006). <marnold@vtr.net>. Texto apresentado no 15² Congresso da SBS (26-29 jul. 2011, em Curitiba); versão anterior publicada como: Las ciencias sociales latinoamericanas, sus condiciones y desafios ante la sociedad del siglo veintiuno (Sinais, v. 1, n. 9, jun. 2011, p. 76-91

\begin{tabular}{|l|l|l|l|l|l|}
\hline Civitas & Porto Alegre & v. 12 & n. 1 & p. 9-19 & jan.-abr. 2012 \\
\hline
\end{tabular}


Las condiciones de producción y la proyección del conocimiento producido por las ciencias sociales están cambiando aceleradamente. Durante este primer decenio del siglo veintiuno se aprecia un reforzamiento del valor atribuido al conocimiento de las condiciones y dinámicas que acontecen en la sociedad, tanto en el plano de la comprensión descriptiva de su estructura y funcionamiento como en el prescriptivo. En este último caso, las explicaciones sociológicas constituyen fondos argumentales para el diseño y legitimación de decisiones de políticas públicas y de estrategias empresariales que afectan a personas, comunidades y países, como también sustentan los argumentos de los cada vez más numerosos movimientos ciudadanos.

Mientras las disciplinas sociales cumplen una función acreditadora para sus públicos, la sociedad complejiza su reproducción, acogiendo y diseminando los resultados de un quehacer originado en los cada vez más numerosos centros académicos que realizan investigaciones y estudios sociales. Dada la relevancia alcanzada por estas prestaciones, estudiar los contextos de producción y difusión de los conocimientos en ciencias sociales y, a la vez, observar lo que ocurre con ello en Latinoamérica, constituye una prioridad.

Las ciencias sociales regionales destacan por su bajo impacto global. Esta situación, más que a una falta de recursos económicos, institucionales o cognitivos, podría atribuirse a las expectativas que nuestras comunidades disciplinarias tienen con respecto a su propio quehacer. Esta explicación parece ser aceptada y compartida, pero no origina propuestas movilizadoras que la modifiquen. Por el contrario, la crítica a la desmejorada posición de nuestras producciones carece de la fuerza requerida, pues se orienta, principalmente, a desacreditar los patrones actuales de la actividad científica y se concentra en denunciar la posición hegemónica de la producción en ciencias sociales que tiene lugar en los países centrales. Si bien la evaluación sobre las hegemonías es correcta, sus efectos pueden ser contraproducentes, especialmente cuando de ella se deriva una invitación a desatender el canon científico vigente; más aún cuando las actuales formas de la actividad científica ofrecen la posibilidad de actuar sobre su construcción.

Un reciente informe de la Unesco sobre el estado de las ciencias sociales destaca que la región latinoamericana, en relación con su creciente volumen de estudiantes e investigadores, presenta, proporcionalmente, una escasa aportación disciplinaria (WSSR, 2010). En ese documento se indica que la expansión cuantitativa de las ciencias sociales regionales, acaecida a partir de la segunda mitad del siglo pasado, no se integra, en forma significativa, al 
conocimiento disciplinario a nivel global, lo cual revela un encadenamiento insuficiente entre una creciente masa crítica de investigaciones y un bajo nivel de aportes con impacto que se estabilicen en la comunicación científica internacional. Aun cuando la producción científica regional se correlaciona estrechamente con las capacidades económicas y las condiciones políticas de nuestros países, ello no explicaría adecuadamente ese déficit.

Desde mediados del siglo pasado se constituye una sociedad mundial, cuyo modo de reproducción en ámbitos específicos como es el de la ciencia, la hace crecientemente indiferente a las diferencias regionales. Las tecnologías info-comunicacionales que han desplazado al papel y la imprenta han acelerado la desterritorialización de la ciencia permitiendo generalizar sus conocimientos casi en tiempo real. Estos mismos medios permiten articular, simultáneamente, procesos investigativos en distintos puntos del planeta. Así, es posible acceder a las nuevas tendencias disciplinarias a través de buscadores especializados, revisando on line las publicaciones más recientes y, si fuese necesario, puede recurrirse a la creciente oferta de traductores en línea. Estos avances, promovidos por la red Internet, deberían estar facilitando, más que obstaculizando, la presencia de las ciencias sociales regionales en el contexto mundial. No obstante estas nuevas facilidades, la compresión de la sociedad mundial y de la región latinoamericana es provista, casi exclusivamente, por una cada vez más diversificada y accesible difusión de conocimientos producidos en las institucionalidades de ciencias sociales de los países occidentales desarrollados.

\section{2}

A pesar de nuestras actuales posibilidades, somos consumidores de las ciencias sociales producidas en los países centrales. Autores como Bourdieu, Giddens, Habermas, Bauman, Foucault, Beck y otros cubren en la práctica todas las materias que deben conocer obligatoriamente quienes se forman en ciencias sociales. Así, nuestra región presenta un crónico abandono y descuido al no considerar el trabajo de sus intelectuales e investigadores, reproduciendo un afianzamiento de relaciones entre centro y periferia que no responde a las nuevas condiciones de la globalización.

La condición anómala que observamos con respecto al desarrollo de nuestras disciplinas a nivel regional requiere ser explicada. Nuestras hipótesis apuntan a destacar el rol conservador de las comunidades regionales de ciencias sociales sobre el valor de sus producciones, y los obstáculos que estas mismas colocan para ponerlas en la primera línea de sus disciplinas. La limitada presencia en la comunicación científica internacional de la producción 
de las ciencias sociales regionales tendría que ver directamente, con las bajas expectativas con las cuales se valoran las producciones de nuestros intelectuales e investigadores. Justamente, por ello, no sería extraño que muchos de ellos encontraran su mayor reconocimiento en el ámbito de la acción política, o sean leídos bajo ese prisma, lo cual oscurece su contribución a la observación sociológica, aunque enaltece su militancia y compromiso social.

No parece productivo desaprovechar las oportunidades que presenta la ciencia global, ni tampoco queda muy claro si es una aspiración deseable constituir un pensamiento sociológico regional desvinculado de los cánones del pensamiento sociológico occidental. Sin embargo, la pretensión universalista de la ciencia social no es aceptada por importantes corrientes de opinión y círculos intelectuales latinoamericanos. Estos, agrupados en las teorías poscoloniales, estudios culturales o subalternos, promueven el desarrollo del pensamiento local con el argumento de que, por ejemplo, las teorías que explican la sociedad estarían encadenadas a sus localizaciones de origen y, en consecuencia, las producciones europeas o anglosajonas no serían válidas en otros contextos. Para los defensores de esta postura, como bien señala Quijano (1992) no hacer esa advertencia sería una señal de sometimiento acrítico, a una razón unilateral y eurocéntrica. Estas ideas tienen ciertamente el valor de invitarnos a poner la atención en la diversidad y el particularismo regional, pero sus declaradas acciones de resistencia frente a los centros hegemónicos, "desobediencia epistémica" según Mignolo (2010), en los hechos, pueden tener efectos no deseados en dos sentidos: relajar la rigurosidad de nuestras investigaciones, pues la crítica no aporta métodos alternativos, o la implícita aceptación de una condición de inferioridad, ante la cual se evita participar en la ciencia. Como en muchos casos equivalentes, la intención es buena revalorizar lo propio -, pero los resultados no tanto.

Desde sus orígenes, las ciencias sociales tienen pretensiones universalistas y no se encuentran razones, ni evidencias, para abjurar de ello. En lo fundamental, y a falta de otros paradigmas y otras "lógicas", no parece razonable suponer, por ejemplo, la existencia de sociedades, culturas y seres humanos en los cuales lo social no sea lo social, la cultura no sea la cultura y los procesos psíquicos no sean procesos psíquicos sino que otra cosa. Las matrices disciplinarias de sociólogos, antropólogos y psicólogos se han identificado con el estudio de la sociedad, la cultura y los procesos psíquicos. Sus instrumentos teóricos o metodológicos no hacen referencia a que los fenómenos constituyentes de sus identidades disciplinarias sean exclusivos de regiones, países, personas o épocas. Sólo por mencionar un ejemplo, desde que se formularon el marxismo, el psicoanálisis o el estructuralismo, sus teorías 
han sido aplicadas en todas las regiones del planeta, en los diferentes países y a los seres humanos de todos los tiempos. Sin ir más lejos, Mariátegui o Paulo Freire, como tantos otros, no descuidaron en sus estudios las aplicaciones del instrumental teórico e interpretativo del marxismo (;finalmente una teoría eurocéntrica!).

Teorías como las indicadas, dado su nivel de abstracción, han sido capaces de abordar tanto la pluralidad y localidad de las expresiones sociales como la unidad que subyace a ellas. Ni siquiera la modelación matemática o la extensiva aplicación de estadígrafos se han propuesto para borrar la diversidad social, cultural y humana, sino más bien para abordar su complejidad y facilitar la comprensión de sus variaciones. Por otro lado, la ciencia moderna exige una actitud crítica hacia sus conocimientos; sus explicaciones se suponen limitadas y provisionales y deben tomarse como puntos de partida para ser susceptibles de colocarse a prueba con investigación y argumentación racional. Por eso, es un capítulo obligatorio de la ciencia social evaluar y colocar permanentemente a prueba la pertinencia y alcance de sus teorías, partiendo por las herramientas que entregan para observar los fenómenos que se someten a su explicación.

A los anteriores argumentos se ha sumado el hecho de que hoy, más que nunca, la universalidad del conocimiento sociológico es más exigida, pues las explicaciones de lo social difícilmente pueden acotarse a regiones del planeta o a estados-naciones específicos. Ciertamente, la comprensión de la sociedad contemporánea, en un contexto de globalización, no puede reducirse a su manifestación occidental que, de partida, es insuficiente para su propia caracterización. Una lectura parcial sobre la sociedad contemporánea hecha desde las ciencias sociales occidentales puede ser abiertamente poco científica, en la medida que pretenda proyectar universalmente la realidad de una región, tiempo o estructura particular. Lo anterior naturalizaría las formas históricas descuidando su carácter contingente y procesual de los fenómenos sociales. Pero tampoco es razonable producir una comprensión sociológica de América Latina prescindiendo de sus contextos.

Antes de proseguir debemos aclarar que nuestras observaciones no constituyen juicios sobre la calidad o importancia de las producciones que no se integran a las normas científicas. Además del saber sociológico hay otras formas de conocimiento de la sociedad, pero esto no debe hacernos perder de vista las diferencias entre sus formas de construcción y criterios de aceptabilidad. La ciencia social tiene sus convenciones distintivas; las creencias populares, los saberes ancestrales, y las religiones tienen las propias. De manera similar, el sentido común o el arte producen y circulan 
conocimientos con sus propios sellos, ninguna de estas formas corresponde a conocimientos subalternos, sólo son distintos.

Sin duda, la popularidad de las críticas que relativizan el quehacer científico refleja algo de desconocimiento de sus reglas de construcción. Eso no extraña, pues la mayoría de los críticos provienen de cultores de formas más creativas de interpretar los fenómenos sociales, culturales y humanos a través de los procedimientos de la literatura y el ensayismo. Ciertamente, un informe científico no rinde como documento literario y excepcionalmente concita interés público, pero tampoco este último cumple con la cientificidad, ni será incluido en una revista disciplinaria. No parece tan malo que estas diferencias se mantengan. De lo que se trata es que la actividad de las ciencias sociales, como otras, es reconocible como productora de tipos de conocimientos sobre la sociedad, diferenciables de otros. Sobre esa base se trazan sus expectativas y estructuras.

Ciertamente, la subordinación a unas "ciencias sociales" cuyos contenidos desvaloren, o no consideren, nuestras particularidades o las inscriban como momentos de un estadio evolutivo inferior o incompleto - declaración explícita de intelectuales regionales del siglo XIX, como Sarmiento y Alberdi, o del siglo pasado con la teoría sociológica de la modernización -, es inaceptable. Tampoco tiene sentido asumir una supuesta superioridad cognitiva del pensamiento eurocéntrico en las ciencias sociales. Una concepción colonialista acerca de la estructura, funcionamiento y cambio de la sociedad, no es científica, su fundamento es un falso universalismo que confunde una parte con el todo y rememora al evolucionismo unilineal, las teorías del progreso y otros relatos teleológicos, a los cuales nadie les atribuye vigencia o los califica de científicos. Pero ese distanciamiento no conduce a la descalificación de la ciencia social moderna, ni fundamenta filtrar los conocimientos según su procedencia y distancia de los centros sociopolíticos dominantes. Estas últimas trayectorias son exageradas y llevan a una suerte de nacionalismo teórico que, como indica un conocido proverbio, significaría botar el agua de la bañera junto con el niño. Tal postura, o sospecha radical como señala Escobar (2003), perjudica la aspiración universalista de nuestras disciplinas, pues, al desligarnos de la construcción disciplinaria, a nuestras ciencias sólo les queda ser elaboradas desde el prisma de centros de investigación de países desarrollados y occidentales. Es decir, reproducirse en forma sesgada y limitada.

El sistema científico de la sociedad se constituye mediante el encadenamiento de evidencias y argumentaciones que dan forma a sus actuales formas estructurales (Luhmann, 1998) y para lo cual deben, metódicamente, 
ser indiferentes a otras consideraciones. Descripciones ampliamente generalizadas en torno a las características de la sociedad contemporánea respaldan las evidencias que indican la mundialización de las instituciones sociales (Stichweh, 2000). Para el caso, coincidimos con las declaraciones de Chernilo y Mascareño $(2005, \mathrm{p}$.17) cuando afirman que no existen regiones particulares del globo que escapen a la presión por una integración normativa universalista ni a las formas de coordinación exigida por la diferenciación funcional. En este sentido, las condiciones que ponen los programas y que se exigen para la certificación de conocimientos científicos, por ejemplo en su capítulo de la ciencia social, obligan de una u otra manera a alinearse con sus estándares. Quienes optan por caminos divergentes asumen como costo no contribuir a modificar los criterios que, en algún momento del tiempo, operan en la ciencia como sus directrices centrales globalmente producidas.

Apartarse de las formas de presentación de los artículos y argumentaciones de la ciencia social de clase mundial podría ser autodestructivo pues, dado el actual patrón de agregación global de los conocimientos, quienes se marginen de sus expresiones validadas, por ejemplo de los formatos de sus publicaciones o de sus criterios de rigurosidad, serán los principales afectados. Siguiendo a Nassehi (2011), estas omisiones constituyen autoexclusiones, pues sólo los textos (comunicaciones) que se enlazan con las formas del sistema científico son componentes del mismo. Lo probable es que una producción paralela sea indiferente para la ciencia, pase desapercibida o forme parte de sus objetos de estudio.

\section{3}

Observar los aportes a las ciencias sociales globales que han realizado científicos sociales en países latinoamericanos puede entregar muchas lecciones. Entre los ejemplos más destacables que dan cuenta de flujos desde la periferia hacia el centro, se encuentran la teoría de la modernización asincrónica desarrollada por Germani (1962), la teoría de la dependencia, en la versión de Cardoso y Faletto (1969), o la teología de la liberación que, para el caso de las ciencias sociales, destaca por hacer una interpretación de la cultura latinoamericana a partir de las formas de devoción popular de la religiosidad católica. Estas teorías estimularon el desarrollo de investigaciones que, profundizando las especificidades regionales, se vincularon con procesos globales y, por su potencia, han hecho importantes contribuciones a las ciencias sociales.

Un estudio reciente (Arnold et al., 2011) ha abordado otro caso en el que la dirección tradicional de la difusión científica se invierte. Se trata del 
impacto de la teoría de la autopoiesis desarrollada por los biólogos chilenos Humberto Maturana y Francisco Varela (1995 [1973]), la cual, como se conoce, fue adoptada por la teoría de los sistemas sociales de Niklas Luhmann en Alemania (1982) y asimilada por la corriente psicológica y constructivista de Palo Alto en los Estados Unidos (Segal, 1986). El impacto del concepto de autopoiesis constituye un caso ejemplar para nuestros argumentos, pues remite directamente a las actuales condiciones estructurales de la sociedad contemporánea. Es una invitación a constatar la efectiva declinación de las tradicionales divisiones regionales del conocimiento, y a observar como estos procesos paulatinamente abren espacios para que producciones científicas originadas en centros periféricos del mundo influyan en el desarrollo del sistema de la ciencia contemporánea, pues: ¿qué otra cosa sino la existencia de una ciencia global, incluso sin fronteras entre campos disciplinarios, fue lo que proporcionó el espacio para que el concepto de autopoiesis pudiera difundirse?

Sin embargo, y no obstante los ejemplos, las alternativas de difusión científica siguen siendo escasas en nuestras disciplinas y refuerzan la suposición de que existen obstáculos, más profundos, que impiden difundir y estabilizar los aportes originados en países periféricos limitando la posibilidad de aprovechar las nuevas condiciones provistas por la estandarización de la comunicación científica de nuestras disciplinas, así como para facilitar la integración de investigadores en redes globalizadas y el uso de nuevos soportes para la difusión de conocimientos.

\section{4}

Para remontar nuestras posiciones en las ciencias sociales globales nos favorecería mucho una rápida integración a las mejores prácticas de las ciencias sociales internacionales, promover su apropiación crítica y creativa a través de organizaciones académicas regionales, como por ejemplo sus centenarias universidades públicas, o de asociaciones como Alas y Clacso. También, hacer valer el tamaño de nuestra comunidad lingüística, pero reconociendo el hecho de que ciertos idiomas, como es hoy el caso del inglés, son los equivalentes al latín que unificó el pensamiento medieval.

En todo caso estamos, a mi juicio, en un punto de inflexión. El futuro congreso de la ISA en Buenos Aires, el reciente Congreso Alas de Recife (2011) (que recibió más de seis mil resúmenes de ponencias), son oportunidades que debemos aprovechar para discutir estas materias y estrechar lazos con tradiciones con las que compartimos aspiraciones y con las cuales podemos enfrentar el desafío de posicionar activamente, en forma colectiva y colaborativa, nuestras disciplinas en el actual contexto global. 
Nuestros planteamientos han sido advertidos y adelantados. El mismo Boaventura de Sousa Santos (2006, p. 26) señaló que hay que intentar hacer que lo que está ausente esté presente. También coinciden programáticamente con Martins (Barros, 2011), cuando promueve una integración creativa de la sociología clásica y moderna, europea o norteamericana, sin caer en un universalismo abstracto, pero tampoco en un particularismo relativista descontextualizado. Todo invita a recuperar la rica tradición del pensamiento social desarrollado por nuestros intelectuales e investigadores, pero, además, a trabajar para apropiarnos, críticamente, de las mejores expresiones de las ciencias sociales contemporáneas, por ejemplo, las teorías de la complejidad (Mejía, 2010) y de la sociedad policéntrica, y a aportar, desde allí, con impacto y efectividad, a una producción de clase mundial. Una propuesta alternativa que sea efectivamente movilizadora conllevaría aplicarnos en acciones científicas, si se quiere contra-hegemónicas, pero dentro del contexto hegemónico, reforzando las investigaciones latinoamericanas que se publican en revistas indexadas del más alto nivel y promoviendo que sean discutidas y referidas globalmente.

Ahora corresponde animarnos a aprovechar las nuevas capacidades disponibles para el desarrollo de investigaciones de amplio alcance que no sean indiferentes al actual contexto mundial. Nos referimos, por ejemplo, a la globalización y sus actuales formas hegemónicas de subordinación de países e identidades; la revitalización de las diversidades sociales y culturales; los efectos de las actuales crisis financieras que afectan los fondos sociales; las nuevas y crecientes desigualdades y exclusiones sociales; la devastación de nuestros recursos medioambientales; la extendida inseguridad y maltrato en las grandes ciudades; los acelerados cambios en la composición etaria de la población; el repliegue de los estados y la desprotección y el individualismo que lo acompañan; los nuevos movimientos sociales, sus luchas reivindicativas y la emergencia de las redes sociales globales y locales, y la transformación de la impaciencia ciudadana en indignación, que son, entre otros, algunos de los conflictos que se despliegan en el mundo contemporáneo y que podrían asumirse desde las ciencias sociales en Latinoamérica.

Finalmente, un llamado para acoplarnos con los procedimientos universalistas de las ciencias no implica neutralidad frente a lo que se indica y describe, no se propone abandonar el interés por los cambios sociales. El productivismo académico y la hipersensibilidad ante la cienciometría no deben descuidar la valorización de la aplicación del conocimiento de las ciencias sociales. Quizá por el contrario, pues lo que más interesa a una propuesta de transformación social efectiva es contar con el conocimiento certero de sus 
condiciones de posibilidad. Por ejemplo, frente a los movimientos ciudadanos, estamos en deuda con el desafío de su esclarecimiento. Sin embargo, antes que nada, para que nuestro posicionamiento empiece efectivamente a formar parte de nuestras expectativas y pueda transmitir este sentido a las nuevas generaciones de investigadores, debemos remover los obstáculos que, hasta ahora, nos impiden beneficiarnos de las oportunidades de la globalización de la ciencia, y esto debe partir por reconocer los aportes de quienes producen en las ciencias sociales regionales y aprovechar las nuevas condiciones que se abren para la construcción de nuestras disciplinas.

\section{Referencias}

ARNOLD, M., URQUIZA, A.; THUMALA, D. Recepción del concepto de autopoiesis en las ciencias sociales. Sociológica, Azcapotzalco, v. 26, n. 73, p. 87-108, mayo-ago., 2011.

CARDoso, F. H.; FALETTO, E. Dependencia y desarrollo en América Latina. México: Siglo XXI, 1969.

CHERNILO, D.; MASCAREÑO, A. Universalismo, particularismo y sociedad mundial: obstáculos y perspectivas de la sociología en América Latina. Persona y Sociedad, Santiago, v. 19, n. 3, p. 17-45, 2005.

BARROS, F. de. A sociologia latino-americana entre os desafios da descolonização planetária e a reconstrução da utopia democrática: uma reflexão a partir da Alas (Entrevista com Paulo Henrique Martins). Centro de Pesquisa e Pós-Graduação sobre as Américas, Brasília, 2011.

ESCOBAR, A. Mundos y conocimientos de otro mundo: el programa de investigación de modernidad/colonialidad latinoamericano. Tabula Rasa, Bogotá, n. 1, p. 51-86, ene.-dic. 2003.

GERMANI, G. Política y sociedad en una época de masas: de la sociedad tradicional a la sociedad de masas. Buenos Aires: Paidós, 1962.

LUHMANN, N. Autopoiesis, Handlung und kommunikative Verständigung. Zeitschrift für Soziologie, Bielefeld, v. 11, n. 4, p. 366-379, out. 1982.

. La ciencia de la sociedad. México: Anthropos, 1996.

. Die Gesellschaft der Gesellschaft. Frankfurt am Main: Suhrkamp, 1998.

MARTINS, P. H. Ensayo sobre la dádiva: un clásico no reconocido de la crítica descolonial, manuscrito, 2011.

- Interrogando las fronteras del conocimiento sociológico: globalización, descolonización y don, manuscrito, 2011.

MASCAREÑO, A.; CHERNILO, D. Obstacles and perspectives of Latin American sociology: normative universalism and functional differentiation. Soziale Systeme, Luzerna, v. 15, n. 1, p. 73-97, 2009.

MATURANA, H.; VARELA, F. De máquinas y seres vivos - autopoiesis: la organización de lo vivo. 3. ed. Santiago: Editorial Universitaria, 1995 [1973]. 
MEJÍA, J. Teoría e investigación social en América Latina. Yuyaykusun, Lima, n. 3, p. $73-86$, nov. 2010 .

MIGNOLO, W. Desobediencia epistémica, pensamiento independiente y liberación descolonial. Yuyaykusun, Lima, n. 3, p. 17-40, nov. 2010.

NASSEHI, A. La teoría de la diferenciación funcional en el horizonte de sus críticas. Revista MAD, Santiago, n. 24, p. 1-29, mayo 2011.

QUIJANO, A. Colonialidad y modernidad/racionalidad. Revista del Instituto Indigenista Peruano. Lima, v. 13, n. 29, p. 11-20, 1992.

SANTOS, Boaventura de Sousa. Renovar la teoría crítica y reinventar la emancipación social (Encuentros en Buenos Aires). Buenos Aires: Claso Libros, 2006.

SEGAL, L. The dream of reality: Heinz von Foerster's constructivism. New York: Norton \& Co., 1986.

STICHWEH, R. Die Weltgesellschat: Soziologische Analysen. Franfurt am Main: Suhrkamp, 2000,

WSSR (World Social Science Report 2010). International Social Science Council, Paris: Unesco Publishing, 2010. Disponible en: <http://unesdoc.unesco.org/images/ 0018/001883/188333e.pdf>.

Recebido em: 14.11.2011

Aprovado em: 29.12.2011 